\title{
A Forma lógica DA LINGUAGEM RELIGIOSA E ÉTICA
}

\author{
John Bolender ${ }^{l}$
}

Resumo: Ludwig Wittgenstein tentou desenvolver, desde 1929, uma abordagem à filosofia da lógica em termos de escalas de medição. Embora mostrasse grande sensibilidade a diversos tipos de escalas, Wittgenstein não estava bem posicionado para fazer seu projeto render frutos, porque a teoria das medidas não começou a fazer avanços significativos antes do final da década de 1940, e continuou desfrutando de um progresso relevante, até os anos 80 . Não obstante, nas suas obras e palestras dos anos 30, Wittgenstein fez diversas tentativas de entender a lógica, ou a "gramática" da linguagem religiosa e ética relativa à medição. Este artigo é uma tentativa de desenvolver algumas dessas ideias que ocorreram a Wittgenstein, na sua fase intermediária, dentro do contexto da evoluçấo posterior da teoria da mediçáo. Especificamente, defende-se que as linguagens religiosa e ética são formas extremas de medição, não empíricas nem fatuais. Elas representam o caso-limite da medição.

Palavras-Chave: Wittgenstein. Forma lógica. Lógica. Teoria de medição. Sistemas proposicionais. Padrôes de medição.

Este artigo enfoca o entendimento da forma lógica da linguagem religiosa absoluta e também da linguagem ética absoluta. O objetivo é fazer algum progresso nessa direção, tratando com mais cautela. Entenda-se por linguagem absoluta, seja religiosa, seja ética, uma linguagem que expresse um sentido do significado da vida, de propósito ou de valor intrínseco. Alegaçóes feitas usando tal linguagem se tornam irrefutáveis. Embora seja possível rejeitar o emprego de tal linguagem, numa dada ocasião, será impossível contradizer uma alegação desse tipo. É preciso distinguir a linguagem absoluta da linguagem do tipo de linguagem ética ou religiosa, as quais podem ser contestadas e refutadas. Em outras palavras, há mais de uma forma de linguagem religiosa,

\footnotetext{
${ }^{1}$ Professor Visitante do Departamento de Filosofia, Universidade do Espírito Santo (UFES), Vitória, ES - Brasil. E-mail: john.bolender@ufes.br

Doutor em Filosofia pela Columbia University in the City of New York. Autor de The self-organizing social mind (The MIT Press).
}

http://dx.doi.org/10.1590/0101-3173.2018.v41n4.09.p155 
e também mais de uma forma de linguagem ética; em cada um dos casos, há a absoluta e a não absoluta.

Meu argumento é que, seguindo as ideias de Ludwig Wittgenstein, circa 1930, torna-se impossível compreender completamente a lógica, sem alguma noção da natureza da medição. Uma representação da realidade é uma medição, e várias relaçôes lógicas entre representaçôes são relaçôes entre mediçôes. Não é possível captar toda a forma lógica de uma proposição elementar, sem apelar para as formas dos padróes de medição. A questão aqui é que tipos de padrão de mensuração cruciais estruturam a forma lógica das proposições das crenças religiosas e éticas absolutas. Cabe observar que tais asserçôes são tipos de mensuração que não transmitem informação alguma. Elas envolvem uma forma extrema de mensuraçáo, numa maneira análoga ao caso do zero, que é um número cardinal: o caso-limite dos números cardinais. A abordagem para se alcançar um entendimento da forma lógica da linguagem absoluta é combinar ideias de Wittgenstein, principalmente o Wittgenstein intermediário, com os desenvolvimentos da teoria da mensuração, em particular as ideias de S. S. Stevens.

\section{Forma Lógica}

Comecemos fazendo algumas observaçôes gerais sobre forma lógica. A noção de forma lógica foi desenvolvida para captar o que há em comum entre exemplos diferentes da dedução. A motivação para formular uma noção da forma lógica veio da observação de que, em muitos casos, instâncias diferentes da dedução compartilham algo semelhante, que pode ser abstraído dos conteúdos específicos.

Considere estes argumentos:

A temperatura é $20^{\circ} \mathrm{C}$ aqui e agora.

Se é $20^{\circ} \mathrm{C}$ aqui e agora, então não é $25^{\circ} \mathrm{C}$ aqui e agora.

Portanto,

A temperatura não é $25^{\circ} \mathrm{C}$ aqui e agora.

O objeto é esférico agora. 
Se agora o objeto está esférico, então ele não é cúbico agora.

Portanto,

Agora o objeto não é cúbico.

Os dois exemplos acima compartilham uma forma que pode ser representada, usando-se a notação do cálculo proposicional:

P.

$\mathrm{P}=>\sim \mathrm{Q}$.

Portanto,

- Q.

Tabelas de verdade podem ser usadas para demonstrar que isso é uma forma dedutivamente válida. Dada a verdade de $\mathrm{P}$ e a verdade de $\mathrm{P}=>\sim \mathrm{Q}$, a verdade da negação de $\sim$ Q seria inconcebível.

No entanto, Wittgenstein percebeu (WITTGENSTEIN, 1929, p. 167, 2005, cap. VIII) como intuitivamente óbvio que o seguinte também é dedutivamente válido:

A temperatura é $20^{\circ} \mathrm{C}$ aqui e agora.

Portanto,

A temperatura aqui e agora não é $25^{\circ} \mathrm{C}$.

Desse modo, dado um padrão único, uma medição dedutivamente exclui qualquer outra. Em qualquer padrão de medição conhecido na ciência, a coocorrência de duas leituras contrastantes é uma impossibilidade lógica. Não apenas o cálculo proposicional, mas até o cálculo de predicados com identidade não podem representar toda a forma lógica. $\mathrm{O}$ cálculo de predicados pode captar a contribuiçáo dos alguns operadores à forma lógica e, ao menos em alguns contextos, um grau da estrutura de uma proposição elementar. Todavia, 
a notação de sujeito-e-predicado não é suficiente para captar toda a lógica das proposiçóes elementares.

Para captá-la, Wittgenstein tentou desenvolver uma representação das inter-relações lógicas entre proposições elementares, em termos de dimensóes de um sistema de proposiçóes, um Satzsystem, cada dimensão sendo representada por um padrão de medição. O seguinte, por exemplo, representa as possibilidades lógicas para a localizaçáo, tamanho e cor de um círculo do campo de visão.

\section{Figura 1}

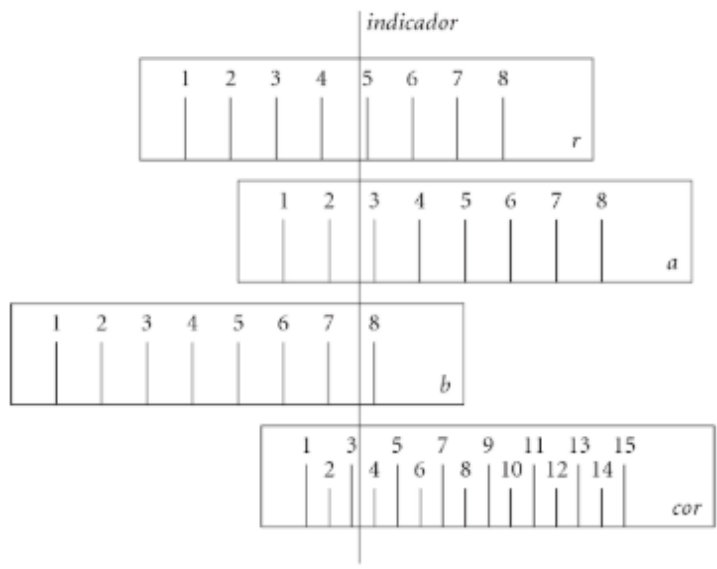

Uma placa de sinais representando as possibilidades lógicas da localização, tamanho e cor de um círculo no campo de visão. Cada padrão de medida representa uma gama dessas possibilidades. $R$ corresponde ao raio do círculo. Altura e largura juntas medem o ponto central do círculo. A concretização de uma possibilidade exclui logicamente qualquer outra, conforme representado pela rigidez do indicador (WITTGENSTEIN, 2005, \$84).

$\mathrm{O}$ padrão de cores corresponde às cores logicamente possíveis. $\mathrm{O}$ padrão marcado $R$ representa o espectro dos raios imagináveis com relação ao campo de visão em questão. A posição do indicador expressa uma proposição elementar. "Pense nas equações da física, na tremenda complexidade de sua estrutura. As proposições elementares também terão esse grau de complexidade." (WITTGENSTEIN, citado por MCGUINNESS, 1979, p. 42). A 
notação lógica aqui é equivalente a uma placa de sinais mais complexa. A impossibilidade de sobrepor leituras contrastantes se reflete na rigidez e na forma reta do indicador e de cada padrão. A geração das proposições moleculares ainda seria, presumivelmente, o resultado de um cálculo definido nos termos da operação recursiva do Tractatus logico-philosophicus (\$5.5).

A rigidez do indicador e dos padróes é crucial, aqui, para a notação lógica (WITTGENSTEIN, 1961, \$6.113), a qual, ao menos, é, de fato, uma notação parcialmente gráfica. A rigidez não é um fato das placas de sinais reais, em todos os casos, mas uma idealização do comportamento de uma placa. É o ponto em Investigaçôes filosóficas na discussão de Maschinensymbol, ou seja, a máquina-como-símbolo (WITTGENSTEIN, 2001, \$193-94; LUGG 2013, p. 148). A lógica de uma dada proposição é constituída por um sistema de proposições, um Satzsystem (2005). Um Maschinensymbol, ou seja, uma representação de uma placa de sinais, é uma parte crucial da representação notacional de um Satzsystem. O Maschinensymbol é necessário para representar a forma lógica do cálculo, o Satzsystem. Em outras palavras, a placa de sinais expressa as relaçôes lógicas entre uma série de proposições elementares. Além disso, uma placa de sinais é constituída pelos padrões de mensuração.

Note-se que, a esta altura, a forma lógica é fundamentalmente um aspecto de um cálculo e do espaço lógico correspondente. Para uma proposição elementar, a sua forma lógica é derivada da forma do cálculo como tal. A concepção da forma lógica aqui é holística, contrastando com a concepção no Tractatus. Como uma tabela de verdade não consegue captar as relaçóes lógicas entre proposiçóes elementares, uma placa de sinais é necessária em seu lugar, e a placa se torna um conjunto indizível.

Se sei que o objeto chega à décima marca de graduação, imediatamente fico sabendo que não chega à décima primeira, à décima segunda etc. As asserçóes que informam a extensão de um objeto compóem um sistema, um sistema de proposiçôes. É esse sistema inteiro o que é comparado com a realidade, e não uma única proposição. (WITTGENSTEIN, 2005, p. 263).

O holismo de Wittgenstein é um desenvolvimento da ideia de que uma proposição, um pensamento, é uma figuração; no entanto, a relação de figuração fica entre o cálculo como uma totalidade e o espaço lógico correspondente. Numa conversa em 1931, Wittgenstein falou explicitamente sobre a equivalência da concepção de uma proposição como uma figuração e a sua concepção como um padrão holisticamente construído: 
Quando escrevi que "uma proposição é uma figuração lógica de um fato", quis dizer que eu poderia inserir uma figuração, ${ }^{[1}$ literalmente um desenho, numa proposição, e então prosseguir com a minha proposição. Desse modo, eu poderia usar uma figuração da mesma forma que uma proposição. Como isso é possível? A resposta é que, simplesmente porque ambas concordam num certo aspecto, e o que elas têm em comum é o que eu chamo de figuração.

Eu também poderia usar uma barra de medição como símbolo, inserir uma barra de medição numa descrição, e usá-la na mesma forma que uma proposição. Pode-se até dizer que em muitos aspectos uma proposição se comporta exatamente como uma barra de medição, e desta forma é possível ter chamado as proposiçóes de barras de medição. (Por exemplo, numa afirmação de cor, podemos confrontar a barra de medição da cor com a realidade). (WITTGENSTEIN, 1961, \$2.1512 citado por MCGUINNESS, 1979, p. 185).

Logo, a forma lógica de uma proposição elementar é dada por uma placa de sinais que consiste de uma coleção de padróes de mensuração, cada um deles correspondnte a uma gama de possibilidades lógicas.

Como um meio de ilustrar a diferença na filosofia da lógica entre o Tractatus e os escritos de Wittgenstein em torno de 1930, considere-se um exemplo de W. V. Quine, apresentado como um meio de representar informaçôes e um certo intervalo de possibilidade lógica. É, de fato, uma versão mais vívida de um exemplo semelhante no Tractatus de Wittgenstein (1961, $\$ 4.063)$.

Consideremos, então, o método de autotipia, na ilustração fotográfica. Uma tela de 15 por 15 centímetros contém uma disposição quadricular, em posiçóes regularmente distanciadas, isto é, 250 por centímetro em fileiras e colunas. A gravura em autotipia é totalmente determinada por um arranjo de 360.000 sinais pretos. A informação, em relação a essa tela, como matriz de alternativas, consiste em assinalar os espaços pretos. Dois quadros transmitem a mesma informaçáo referente a essa matriz, quando fixam, em preto, os mesmos sinais. [...] Outrossim, uma especificação verbal dos sinais presta, em relação a essa matriz, uma informação idêntica à do quadro. (Este constitui o princípio da transmissão de descrições através do telégrafo.) (QUINE, 1972, p. 16). 
Na maneira do Tractatus, a condição de cada ponto pode ser interpretada como um fato atômico. Se o ponto é preto, a proposição elementar "X é preto" é verdadeira, onde X representa o nome do determinado ponto. Caso contrário, a proposição elementar é falsa. A verdade ou a falsidade de qualquer proposição elementar é independente da de qualquer outra, em relação a esse sistema modesto. Contradição e implicação, além do caso-limite de autoimplicação, são apenas encontradas no nível molecular. O número total de possíveis atribuiçôes de valores de verdade seria de $2^{360.000}$ (WITTGENSTEIN, 1961, \$4.27).

Na sequência, vamos variar o exemplo um pouco, de modo que as dimensôes sejam contínuas, como pela aparente percepção de vários espaços sensoriais. "Deparamo-nos com as formas de espaço e tempo [juntamente] com todo o múltiplo de objetos espaciais e temporais, como cores, sons etc. etc., com suas gradações, transiçôes contínuas e combinações em várias proporçôes, todas as quais não conseguimos apreender com nossos meios de expressão comuns." (WITTGENSTEIN, 1929, p. 165). Ora, o número de atribuiçóes de valores de verdade torna-se infinito não-contável, mesmo que se presuma que qualquer ponto seja preto ou não-preto, sem outra opção. $\mathrm{O}$ número de atribuiçóes de valores de verdade teria a multiplicidade do continuum: "No que diz respeito à sua representação, números (racionais e irracionais) devem entrar na estrutura das próprias proposições atômicas." (WITTGENSTEIN, 1929, p. 165). Também não há motivos para limitar-nos a apenas as opçôes de preto e não-preto: um espectro contínuo de cores pode ser usado, a fim de representar as possibilidades cromáticas de cada ponto. Essa concepção fenomenologicamente mais realista de possibilidade lógica é mais bem representada por escalas de medição, com suas propriedades holísticas, do que pela noção atomística de proposiçôes elementares logicamente independentes. Entretanto, note-se que mesmo o exemplo original de Quine pode ser concebido em termos de escalas de medição: a escolha binária entre preto e não-preto pode ser entendida em termos de uma escala nominal muito elementar.

Uma pergunta que surge aqui é se a expressão ética ou religiosa também pode ter essa forma, ou se ficaria fora de lógica, nessa concepção. Em que sentido, se houver, uma expressão da fé religiosa seria uma figuração, uma medição? Em que sentido, se houver, seria possível se pensaar em um espaço lógico para a ética? 


\section{O DESENVOLVIMENTO DA ATITUDE DE WiTtGeNSTEIN SOBRE A IDEIA DE ALGO ESTAR ALÉM DA LÓGICA}

Na busca por uma resposta à questão, comecemos com uma discussão do primeiro tratamento longo que ele fez da lógica. No Tractatus, Wittgenstein $(1961, \$ \$ 6.421,6.44)$ usou o termo "místico", para apontar os assuntos de ética e estética. A ocorrência da palavra "Deus", nesse contexto (\$6.432), e as associações históricas da palavra "místico" sugerem a inclusão do assunto religião. Ocorre que a lógica diz respeito a relaçôes de implicação dedutiva entre proposiçôes. Uma proposição é uma mensuração, ou seja, uma figuração de um fato. Mas a ética, a estética e Deus ficam além dos fatos e, portanto, além da lógica, segundo essa visão. "místico":

Em 1929, Wittgenstein usaria o termo "sobrenatural" em lugar de

Nossas palavras, usadas tal como o fazemos na ciência, são recipientes capazes somente de conter e transmitir significado e sentido naturais. A ética, se ela é algo, é sobrenatural e nossas palavras somente expressam fatos, do mesmo modo que uma taça de chá somente pode conter um volume determinado de água, por mais que se despeje um litro nela. (WITTGENSTEIN, 1965, p. 7).

A palavra "sobrenatural" é divisível em elementos com significados bem relevantes. Assim, "sobre" indica ser além ou de fora. "Natural" indica o mensurável, especialmente à luz do conceito de ciências naturais de Wittgenstein. Desse modo, o sobrenatural é o imensurável, o que está além da linguagem. "É claro que a ética não se deixa exprimir." (WITTGENSTEIN, 1961, \$6.421). Estando além da linguagem, o sobrenatural fica além da lógica.

O sobrenatural se situa além da mensuração, devido a uma tenacidade absoluta diante dos fatos. Suponha-se que a felicidade fosse um valor absoluto. Isso significaria que uma descoberta demonstrando que a felicidade não é um valor seria inconcebível. Não há como ter provas contrárias à autoridade de um valor intrínseco. Isso não é como uma mensuração, em seu sentido comum de "mensuração". Dada a mensuração da velocidade de uma bala, é concebível que uma nova mensuração contradiga a primeira. Qualquer previsão científica pode ser contradita por uma mensuraçáo conflitante. Ao menos, é possível haver uma "anomalia". 
Todavia, para a alegação de que a felicidade é um valor, a noção de anomalia seria uma tolice. Por outro lado, uma alegação de valor relativo equivale a uma mensuração, por exemplo, a afirmação generalizada de que o socialismo é a espécie de sociedade com a maior probabilidade de aumentar felicidade. Trata-se de uma alegação científica, e é possível imaginar fatos que a refutariam, ou ao menos anomalias na afirmação. Uma afirmação de valor, que expresse um meio para se atingir um fim, será uma mensuração. "Por exemplo, se digo que esta é uma boa poltrona, isto significa que esta poltrona serve para um propósito predeterminado e a palavra bom aqui tem somente significado na medida em que tal propósito tenha sido previamente fixado. De fato, a palavra bom no sentido relativo significa simplesmente que satisfaz um certo padrão predeterminado." (WITTGENSTEIN, 1965, p. 5).

Em contrapartida, a expressão de um valor absoluto é compatível com qualquer fato. Nessa perspectiva, é semelhante a uma verdade lógica. Por outro lado, também é semelhante à impossibilidade lógica, visto que nem tautologias e nem contradiçôes são figurações (mensurações): "Tautologia e a contradição não são figurações da realidade. Não representam nenhuma situação possível, porquanto aquela permite tôdas as situaçóes possíveis, esta, nenhuma." (WITTGENSTEIN, 1961, \$4.462). Aparentemente, isso é ligado à discussão da linguagem da religião, em "A lecture on ethics", mais especificamente à expressão de maravilhas em linguagem. Wittgenstein nos dá dois exemplos de maravilhas: um é uma necessidade lógica, o outro é uma impossibilidade lógica. Não chega a ser uma figuração (mensuração) de qualquer coisa. No primeiro exemplo, é a maravilha da existência do mundo, porém, de fato, dada a concepção de Wittgenstein, esta é a maravilha que há em qualquer fato. Sentir o miraculoso nisso é como sentir o miraculos no céu como sendo qualquer cor em tudo. Em outras palavras, o próprio fato de haver a possibilidade lógica já é uma maravilha. "Assombro-me do céu seja lá o que ele for. Poderíamos nos sentir inclinados a dizer que estou me assombrando de uma tautologia, isto é, de que o céu seja ou não azul. [...] Sinto-me inclinado a dizer que a expressão linguística correta do milagre da existência do mundo — apesar de não ser uma proposição na linguagem — é a existência da própria linguagem." (WITTGENSTEIN, 1965, p. 9).

A possibilidade da comunicação não é a questão, ao se discutir aqui a linguagem. O foco é a existência das relaçóes lógicas entre proposiçôes. De vez em quando, Wittgenstein tinha uma sensação de segurança absoluta, uma impossibilidade lógica e um outro exemplo de milagre. Eis dois exemplos da 
linguagem religiosa: "Porque a primeira delas é, segundo creio, exatamente aquilo a que as pessoas se referem quando dizem que Deus criou o mundo; e a experiência da segurança absoluta tem sido descrita dizendo que nos sentimos seguros nas mãos de Deus." (WITTGENSTEIN, 1965, p. 10). E isso não é nem uma figuração nem uma medida. No contexto de "A lecture on ethics", nem a linguagem religiosa, nem uma linguagem que expresse valores absolutos, constitui mensuração. O sobrenatural é o imensurável. $\mathrm{O}$ sobrenatural, para Wittgenstein, era um tipo de experiência ou algo que era revelado nela. Em "A lecture on ethics", Wittgenstein tentou mostrar a natureza do tópico, descrevendo situaçóes onde ele passaria por tal experiência, por exemplo, o sentido do miraculoso, ao pensar na existência da possibilidade lógica.

No entanto, no mesmo ano, Wittgenstein observou que uma notação lógica deve refletir a lógica dos fenômenos em questão. "[T]ais regras não podem ser estabelecidas até que tenhamos, de fato, atingido a análise última dos fenômenos em discussão." (WITTGENSTEIN, 1929, p. 171). No contexto da filosofia da lógica de Observaçóes filosóficas, isso significaria que a placa de sinais deve refletir a forma lógica do espaço lógico em discussão. Isso leva a uma pergunta, visto que há experiências do sobrenatural, por exemplo, uma sensação da maravilha, da obrigação absoluta: é possível que uma placa de sinais, um Maschinensymbol, para o sobrenatural, tenha sua própria lógica?

Em 17 de dezembro de 1930, Wittgenstein considerou a possibilidade de a expressão religiosa não estar fora da linguagem, indicando uma mudança de ideia. Em uma conversa sobre religiáo, ele disse: "Indo de encontro aos limites da linguagem? Afinal de contas, a linguagem não é uma gaiola." (WITTGENSTEIN citado por MCGUINNESS, 1979, p. 117). Treze dias depois, conversando com Friedrich Waismann, Wittgenstein defendeu a possibilidade dos Satzsysteme (cálculos) vazios, isto é, casos-limite de lógica e de linguagem. Fazendo-os, por implicação, criou um espaço na linguagem para a religião e valores absolutos. Durante a conversa, Waismann (citado por WITTGENSTEIN, 2005, p. 271) destacou o seguinte:

Imagine, por exemplo, o caso em que permito qualquer movimento no xadrez e não proíbo nada - isso ainda seria um jogo? As regras de um jogo não têm então de continuar a ser dotadas de certas propriedades para definirem qualquer jogo que seja? Não poderíamos, então, entender a exigência de consistência como exigência de exclusão do jogo 'tautológico'- o jogo em que qualquer coisa é permissível? 
Em resposta, Wittgenstein (2005, p. 271) comentou:

Uma classe de normas e proibiçóes faz fronteira com outra classe de normas e proibiçóes, mas um jogo não faz fronteira com um não-jogo. $\mathrm{O}$ jogo 'tautológico' tem de surgir na qualidade de caso-limite dos jogos, de seu limite natural. O sistema de jogos tem de ser delimitado a partir de dentro, e esse limite consiste simplesmente no fato de que as regras do jogo desaparecem.

É provável que o raciocínio dele, nesse caso, seja fundamentalmente o mesmo usado num argumento do Tractatus: "Tautologia e a contradição não são, porém, absurdas; pertencem ao simbolismo do mesmo modo que ' 0 ' pertence ao simbolismo da aritmética." (WITTGENSTEIN, 1961, \$4.4611). O zero é incluído entre os números cardinais, por ocupar uma posição na linha dos números e porque as operaçóes de adição, subtração e multiplicação se aplicam a ele. No entanto, o zero é um limite da série de números cardinais. Analogamente, é possível ter um Satzsystem que constitua um caso-limite entre os Satzsysteme; ou seja, uma lógica que constitua tal caso, entre as lógicas.

É possível captar a forma lógica do sobrenatural, em um Satzsystem? Dado que o sobrenatural corresponde ao logicamente necessário ou ao logicamente impossível, deve ser um tipo de Satzsystem de caso-limite. Deve ser um tipo de representação que não possa expressar informação empírica. Deve ser um sistema de proposiçóes de fé.

Durante a década de 1930, mas depois da conversa com Waismann sobre casos-limite, Wittgenstein começou a analisar alguns casos de linguagem religiosa de modo diferente. Em vez de asseverar que a linguagem religiosa é uma tentativa de ultrapassar os limites de linguagem e, pois, os limites da lógica, Wittgenstein a considerou como um tipo de linguagem com uma lógica bem especial. "Imagine que alguém esteja doente e diga: 'Isso é um castigo'. Então eu respondo: 'Quando eu fico doente, nem penso em castigo.' Se você retrucar: 'E você acredita no contrário?' - poderá chamar isso de acreditar no oposto, porém será totalmente diferente do que normalmente chamaríamos de acreditar no oposto." (WITTGENSTEIN, 1967, p. 55). O Satzsystem religioso em discussão é equivalente a uma placa de sinais, um Maschinensymbol, onde nenhuma leitura tem qualquer significado empírico. Uma proposição gerada por esse sistema não pode contradizer nada empírico, como um sistema que só consiga gerar tautologias. De fato, no contexto do sistema, não há nada que possa contradizê-la. No contexto do sistema, não é possível refutar uma 
afirmação, porém, é possível decidir não utilizar o próprio sistema, em primeiro lugar. $\mathrm{O}$ sistema incorpora uma lógica, mas é um caso de limite da lógica, assim como o zero é o caso de limite de ser um número cardinal.

Os Satzsysteme que geram proposições com conteúdo empírico são notavelmente diferentes disso. "Imagine um crente que dissesse: 'Acredito no Juízo Final', e eu respondesse: 'Bem, eu não tenho tanta certeza. É possível.' Você diria que há um enorme abismo entre nós. Mas se ele dissesse 'Há um avião alemão lá em cima' e eu respondesse: 'É possível, mas não tenho tanta certeza', você diria que estamos bem mais próximos." (WITTGENSTEIN, 1967, p. 53). Aqui se apresenta um contraste entre dois tipos de lógica. No primeiro caso, a expressão da ocorrência futura de um Juízo Final é análoga à expressão de um valor absoluto. Se eu insistir que a felicidade é um valor intrínseco, uma prova contraditória não será concebível. Da mesma forma, se eu insistir que haverá um Juízo Final, isso é uma questão de fé, e uma prova contraditória não será concebível. O único meio de "contradizer" a afirmação é optar por não utilizar o Satzsystem, em primeiro lugar. Todavia, no segundo, caso uma contradição é possível, sem rejeitar o sistema como um todo. "Possivelmente, não tenho certeza”, nesse contexto, seria normalmente a expressão da possibilidade de contradição entre mensuraçóes, usando o mesmo padrão, mas não necessariamente a possibilidade da rejeição do próprio padrão.

Usando de mais cautela, na década de 1930, Wittgenstein reconheceu ao menos dois tipos de lógica, na linguagem religiosa: em algumas instâncias, ela incorpora o caso-limite sem conteúdo empírico; em outras, incorpora padrôes para a mensuração empírica. A religião, no segundo sentido, é um tipo de ciência. Wittgenstein, no entanto, mostrou-se cético quanto à confiabilidade da religião, nesse segundo sentido. Vejam-se estes trechos das anotaçóes de G. E. Moore, numa palestra de Wittgenstein sobre a linguagem religiosa: "Ou então no caso de uma pessoa agonizante, acha-se que se distanciou muito. Imagine se você tiver criado uma teoria, e falar sobre a distância entre o corpo e a alma. É nesse momento que começará o besteirol." (WITTGENSTEIN citado por CITRON, 2013, p. 28). O besteirol aqui indica alegaçốes com conteúdo empírico, mas muito implausíveis. A afirmação de que a pessoa sobrevive à morte, e a tentativa subsequente de medir a distância entre alma e corpo seria o uso de um padrão de medição das ciências, contudo, de uma maneira sem interesse científico (CITRON, 2013). Desse modo, há pelo menos dois tipos de lógica, na linguagem religiosa: uma lógica do sobrenatural, no sentido dis- 
cutido anteriormente; e, por outro lado, uma lógica da mensuração, usando-se os padróes apropriados à ciência.

No curso de uma discussão, é possível observar, às vezes, um fluxo entre lógicas diferentes para os mesmos termos religiosos ou éticos: "Se observamos o uso efetivo de uma palavra, o que vemos é algo constantemente flutuando." (WITTGENSTEIN, 2003, p. 55). Com efeito, além de distinguir a linguagem de valores absolutos da linguagem de valores relativos, também podemos distinguir a linguagem religiosa absoluta da linguagem religiosa (pseudo-) científica. A esta altura, podemos simplificar a nossa terminologia, tratando de "linguagem absoluta", um termo para incluir ambos, tanto a linguagem dos valores absolutos como as afirmaçôes da fé religiosa. A caracterização da linguagem absoluta requer mais do que a discussão das propriedades formais, como jogos de casos-limite ou Maschinensymbole. Há igualmente um elemento de importância, um sentido de propósito, um aspecto profundamente emocional, frequentemente associado a um sentido do significado da vida.

Wittgenstein teve grande consciência desse aspecto. E ele também distinguiu a expressão emocionalmente fria das ciências da expressão emocionalmente quente dos absolutos: "A ética, na medida em que brota do desejo de dizer algo sobre o sentido último da vida, sobre o absolutamente bom, o absolutamente valioso, não pode ser uma ciência. O que ela diz nada acrescenta, em nenhum sentido, ao nosso conhecimento." (WITTGENSTEIN, 1965, p. 12). Discutindo a crença na sobrevivência da alma antes da morte, Wittgenstein (citado por CITRON, 2013, p. 28) observou:

Alguém poderia pensar que essas pessoas acabaram de cometer um erro científico. Contudo um simples erro jamais significa tanto para ninguém. Esta e muitas outras perguntas sempre foram tratadas de duas formas, uma quente e outra fria. E quando se trata isso a frio, se resultar um absurdo, isso não provará que resulte um absurdo quando se tratar a quente.

Dado o escopo do artigo, não posso acrescentar mais nada sobre esse aspecto da linguagem absoluta, no entanto, em uma discussão completa dessa linguagem, exigiria muitos detalhes.

Vimos que, ao menos no caso das proposiçóes elementares, a natureza da mensuração desempenha um papel crucial nas relações lógicas. Uma gama de possibilidades lógicas é bem representada por meio de um padrão de medição, ou de um conjunto deles para captar as várias dimensôes de possibili- 
dade. O resultado é que a lógica de cada sistema de proposiçóes elementares (Satzsystem) pode ser efetivamente representada por meio de uma placa de sinais (Maschinensymbol), conforme se mostra na figura 1.

Wittgenstein pensava que a linguagem da religião, pela expressão dos valores absolutos, ia além da lógica, porque não correspondia a nenhum tipo de padrão de medição. Mais tarde, em 1930, ele aventou a possibilidade de um sistema de caso-limite e, subsequentemente, a possibilidade de tais formas de linguagem corresponderem a lógicas bem especiais.

A seguir, vamos considerar o desenvolvimento da teoria de mensuração, a partir da década de 1940. Isso ajudaria no propósito de entender melhor a significância dos padróes de caso-limite.

\section{Padrốes de Mediçáo}

Lembremos o desacordo entre Waismann e Wittgenstein sobre os “jogos tautológicos", ou seja, os cálculos que náo podem ser usados para transmitir qualquer informação (MCGUINNESS, 1979, p. 131-33; WITTGENSTEIN, 2005, p. 270-71). Para Waismann, pode-se aplicar regras do metanível para negar àqueles o estado de cálculos genuínos. Em contrapartida, conforme Wittgenstein, arrumar regras do metanível já é pressupor que haja uma gama de cálculos que inclui casos de limite.

Deve-se pressupô-los, para excluí-los: "Não posso chegar a esse limite mediante o estabelecimento, feito por mim, de regras e proibições específicas; porque isso, mais uma vez, me dá mais um jogo entre muitos." (WITTGENSTEIN, 2005, p. 271). O argumento de Wittgenstein é similar à afirmação clássica de que zero é um número cardinal, notoriamente por ocupar uma posição na escala de números. Não se pode traçar um ponto divisor na escala numérica completa, sem, ironicamente, incluir o zero.

Anos mais tarde, um desentendimento semelhante surgiu entre S. S. Stevens e Brian Ellis, sobre o que se considera um padrão de medição. Assinala Stevens: "A medição é a atribuição de numerais a objetos ou eventos seguindo uma regra - qualquer regra." (STEVENS, 1959, p. 19). Ellis rejeitou essa concepção liberal de mensuração, alegando que ela incluiria padrôes que não podem ser usados para transmitir qualquer informação. Por exemplo, um padrão onde exista a regra de se aplicar o mesmo número para tudo não poderia ser usado para fazer qualquer discriminação (ELLIS, 1966, p. 39-42). Além 
disso, a atribuição aleatória de números às coisas seria igualmente inútil para transmitir qualquer informação. Um padrão assim não teria utilidade científica nenhuma e, portanto, não seria um padrão, ao menos sob o ponto de vista de Ellis.

Antes de entrar em detalhes da teoria da mensuração, é preciso considerar relevante essa questão sobre a forma lógica da linguagem religiosa e ética. A linguagem de valor absoluto, ou de fé religiosa absoluta, é um idioma desprovido de conteúdo fatual. Pode-se optar por não usar essa linguagem, mas não é possível se contradizer, visto que não se afirma nada, ao usá-la. Seu significado é emocional, algo que lhe confere um sentido de significado ou propósito para a vida. Não se pode discutir uma afirmação ética absoluta, pela mesma razão que não é possível questionar um artigo de fé religiosa: é a expressão de uma atitude para com a vida, mais do que a diferenciação entre um possível estado de coisas e outro. Se existem cálculos ou Satzsysteme de fé religiosa, ou valores éticos absolutos, estes, ao menos parcialmente, consistiriam de um padrão de medição do tipo caso-limite rejeitado por Ellis. Rejeitar o caso-limite padrão como um padrão genuíno equivaleria a rejeitar a tal linguagem religiosa/ética como isenta de lógica. Seria o mesmo que sustentar que o objeto de fé absoluta e os valores absolutos seriam algo fora da lógica, fora da linguagem, fora da medição, como na verdade era a visão de Wittgenstein, na década de 1920 . Contudo, reconhecer o padrão do caso-limite seria ter uma visão mais liberal da lógica e, assim, da possibilidade de linguagem religiosa/ética.

Alega-se que, assim como o zero é um número cardinal em decorrência de ter seu lugar na sequência numérica, o caso-limite padrão é uma mensuração, em virtude de ocupar um lugar na cadeia do subgrupo decrescente dos padrōes de medição (NARENS, 1981). Afirmar que os tipos de padrão formam uma cadeia de subgrupos é tratar das simetrias de cada tipo (NARENS; LUCE, 1986). Uma simetria de um tipo de padrão de medição é uma transformação permissível, e uma transformação admissível é uma permutação que não resultaria em nenhuma perda de informação. Em outras palavras, se for possível executar uma operação matemática no padrão, transformando-o num padrão diferente, mas sem qualquer perda de informação, terá sido executada uma transformação admissível.

Por exemplo, a multiplicação de cada numeral do padrão Kelvin por 2 resultaria em um novo padrão, porém, com os mesmos poderes de representação que um padrão Kelvin. Adicionar 1 a cada numeral seria uma transformação inadmissível, visto que a informação seria perdida. $\mathrm{O}$ padrão resultante 
não mais exprimiria relaçóes; ou seja, trata-se de uma transformação inadmissível no padrão da razão. Por outro lado, adicionar 1 a cada numeral seria uma transformação admissível no padrão de intervalo; por exemplo, adicionar 1 a cada numeral de graus no padrão Celsius simplesmente produziria um outro padrão, capaz de expressar precisamente as mesmas informações que o padrão Celsius. Isso significa que o padrão de intervalo tem mais simetrias do que o padrão da razão. Todavia, note-se que, em virtude de possuir mais simetrias, o padrão de intervalo transmite menos informaçóes do que o padrão da razão. Por exemplo, o padrão Celsius, ao contrário do padrão Kelvin, não pode expressar razóes, uma vez que ele não tem um zero absoluto.

$\mathrm{O}$ conjunto de simetrias do padrão de razão, em outras palavras, seu grupo, é um subgrupo das simetrias do padrão de intervalo. O grupo do padrão de intervalo é um subgrupo do grupo do padrão ordinal, este último sendo simplesmente o arranjo de coisas em uma série, tais como a classificação de estudantes. Classicamente, o tipo mais fraco de mensuração é o padrão nominal, que trata simplesmente de colocar coisas em categorias distintas. Numerais em padrão nominal são usados apenas como rótulos, como a identificação de carros de corrida por números. Qualquer transformação conta como uma transformação admissível, desde que a quantidade de numerais permaneça a mesmo. Isso é tudo o que é necessário para expressar a mesma informação. Portanto, o grupo do padrão ordinal é um subgrupo do grupo do padrão nominal. As simetrias são mais associadas ao padrão, quanto menos informação transmitirem. Um padrão do caso de limite seria absolutamente simétrico, transmitindo zero informaçóes.

O ponto pode ser ilustrado, tendo-se em vista os tipos de classificação dos alunos. Atribuir notas percentuais a estudantes (padrão de razão) transmite mais informação do que lhes atribuindo notas com letras (padrão de intervalo). A classificação de alunos (padrão ordinal) transmite ainda menos informações, porém, ainda transmite mais informaçôes do que a escolha (padrão nominal). $\mathrm{O}$ caso-limite pode tomar qualquer uma das duas formas: atribuir o mesmo número para todos os alunos, não importando o seu desempenho, ou atribuir números aleatoriamente. Em ambos os casos, qualquer transformação concebível seria admissível e, portanto, o padrão seria perfeitamente simétrico. No entanto, precisamente por essa razão, ele não poderia transmitir nenhuma informação sobre o desempenho dos alunos. O fato de qualquer transformação ser admissível simplesmente reflete o fato de que não há nenhuma infor- 
mação a se perder. Mesmo assim, haveria uma posição de limite na gama dos possíveis tipos de padrão.

Além disso, já que certas operaçóes aritméticas podem ser aplicadas a zero, como a multiplicação, o padrão do caso-limite tem igualmente seu papel na medição, ou seja, a mediçãao não discriminatória implícita na fé inabalável.

Wittgenstein verificou que existem diferentes tipos de medição. Com efeito, a variedade de tipos de padrão de medição parece ter sido sua primeira evidência, como base para afirmar que as formas lógicas são heterogêneas. A julgar por seus exemplos, Wittgenstein também estava ciente dos tipos de medição distintos do intervalo e da razão: "Se digo que não sonhei na noite passada, ainda tenho de saber onde eu teria de procurar um sonho (isto é, a proposição 'eu sonhei', aplicada a essa situação, pode ser, no máximo, falsa, mas não sem sentido). Exprimo a situação atual por sim posicionamento - o negativo — da placa de sinais 'sonhos — nenhum sonho'." (WITTGENSTEIN, 2005, \$86). Esse padrão de mensuração teria apenas duas categorias, como o padrão preto/não-preto na matriz de Quine. Sendo simplesmente um conjunto de categorias, seria um padrão nominal.

Normalmente, um padrão de medição envolve uma variável que pode abarcar mais de um valor. Os casos extremos que Ellis descarta e Stevens permite, ao menos por implicação da definição dele, são casos nos quais qualquer valor possível para a variável dada seria equivalente a qualquer outro. Como um cálculo, seria absolutamente rígido, visto que todas as leituras possíveis da placa de sinais seriam equivalentes. Por outro lado, para o cálculo não de caso-limite, a variável dada pode assumir valores diferentes. $\mathrm{O}$ cálculo pode, assim, transmitir informaçóes.

\section{Os CÁlCUlos MORAIS E RELIGIOSOS}

Um Satzsystem wittgensteiniano é frequentemente o resultado da combinação de vários padróes de medição, e não necessariamente todos do mesmo tipo. Por exemplo, uma dimensão pode ser expressa por uma escala de razão que indica a posição espacial, enquanto a dimensão da cor pode ser representada por uma escala nominal. A última poderia ser, por exemplo, uma pequena lista de cores possíveis. Um espaço de possibilidades lógicas pode ser delineado pela combinação de tipos contrastantes de padrão. 
Um Satzsystem para expressar os ideais éticos absolutos, ou crenças religiosas absolutas, deve consistir de pelo menos um padrão "rígido", no sentido discutido acima. Mas isso não significa que o sistema não possa ser composto de padrôes contendo também informações. Se alguém for tentar representar um Satzsystem desses, por meio de uma placa de sinais, de forma análoga para a placa na figura 1, como iria proceder? Uma sugestão imaginável seria tomar a placa da figura 1 e alterá-la para que houvesse apenas um valor possível para $R$, o padrão de $R$, perdendo assim seu significado empírico. Entretanto, estaria $R$ servindo para qualquer função na determinaçáo da forma lógica do sistema? Parece meramente decorativo. A fim de conferir-lhe o padrão de caso-limite, ele deveria ter alguma função, de sorte que seja a de pivô para o indicador, como em um medidor ou cronômetro (figura 2).

\section{Figura 2}

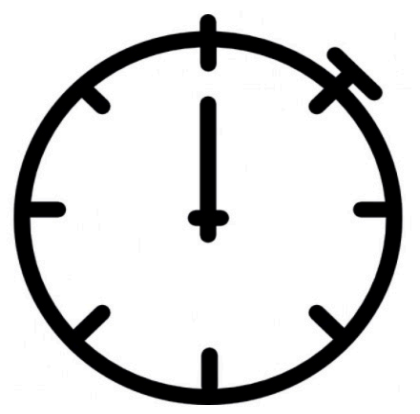

Fonte: Domínio público

Por exemplo, o pivô poderia representar um valor absoluto ou uma condenação que tornasse possível aplicar um padrão de intervalo, determinando os valores relativos dos resultados empiricamente possíveis. $\mathrm{O}$ indicador pode fazer variar os valores de intervalo, em virtude do giro sobre uma medida fixa. O padrão de ponto fixo empiricamente vazio torna possíveis as séries de intervalo representadas pelo padrão curvo, em torno da circunferência do mostrador do cronômetro, na figura 2.

Uma ilustração vívida desse tipo de Satzsystem é encontrada no sistema de valor do militante radical do século XIX, Sergey Nechayev, como se reflete 
em seu panfleto Catecismo de um revolucionário. Segundo Nechayev (2011, \$22), a associação dos revolucionários

não tem outro objetivo que a emancipaçáo total e a felicidade do povo, quer dizer, da parte da humanidade constrangida a trabalhos duros. Mas, persuadido que esta emancipação e esta felicidade não podem ser atingidas senão através de uma revolução popular que destruirá toda a sociedade, a associação colocará tudo em curso para aumentar e multiplicar os males e os sofrimentos que encolerizaráo a paciência do povo e desencadearáo a sua revolta massiva.

Por essa razão, para o revolucionário, "o que é moral, é o que favoriza o triunfo da revolução, o que é imoral e criminoso, é o que a contraria.” (\$4). Aqui temos um padrão rígido: no que se refere à revolução, apenas um único julgamento é possível, ou seja, a atribuição de um valor absoluto para o seu triunfo. No entanto, note-se: "É no mesmo propósito que se dedica, dia e noite, ao estudo das ciências da vida: os homens, os seus caracteres, as suas relaçôes entre eles, assim como as condições que regem em todos os domínios a ordem social atual. O objetivo é sempre o mesmo: destruir o mais rapidamente e o mais seguramente possível esta ignomínia que é a ordem universal." (\$3). Aqui temos um padrão contendo informaçôes, o que seria mais comumente conhecido como "medida" $\mathrm{e}$ - algo que não surpreende - uma referência à ciência. $\mathrm{O}$ uso de um padrão contendo informaçóes aqui depende da premissa absolutamente rígida de que a revolução deverá ser bem-sucedida. Caso contrário, não haverá meios de se colocar linhas de ação possíveis numa classificação ordinal. Em outras palavras, usa-se o padrão contendo informaçóes para medir a eficácia de um determinado curso de ação, a fim de promover a causa revolucionária: uma combinação de padráo de caso-limite e padrão contendo informaçóes, de maneira a formar um único sistema proposicional de valores morais.

Também se encontram em casos de linguagem religiosa. Apesar da falta de conteúdo fatual, a fé absoluta pode servir como base para a tomada de decisóes, utilizando um padrão contendo informaçóes. Por exemplo, a fé absoluta na inspiração divina do Alcorão e Hadith pode servir como meio para classificar atos em termos de moral, se valer a pena, um aplicativo de padrão ordinal.

Ele também pode servir como meio para decidir as recompensas e puniçốes apropriadas, como é o caso do Hadith, que inclui a lei islâmica. Garantir que o crime receba punição e que o ato virtuoso receba recompensa é achar a proporção certa, a razão correta. Isso é um padrão de razão (FISKE, 1991). 


\section{ConClusấo}

Wittgenstein iniciou um projeto para compreender a possibilidade lógica, em termos de escalas de medida. Abandonou o projeto, optando por uma abordagem relativamente antiteórica à filosofia da lógica, evidente em suas Investigaçóes filosóficas. De fato, Wittgenstein não estava bem posicionado para desenvolver uma teoria dessas, na década de 1930, porque a teoria da medição ainda não estava bem adiantada, na época. Quando a teoria da medição começou realmente a avançar (STEVENS, 1946), Wittgenstein já havia concluído a maior parte de suas Investigaçóes filosóficas. Desenvolvimentos importantes posteriores na teoria da medição, em termos de grupos de simetria (NARENS 1981; LUCE; NARENS 1986), ocorreram após a morte de Wittgenstein.

Assim, é um projeto válido tentar desenvolver a filosofia da lógica de Wittgenstein, na sua fase intermediária, quanto aos avanços posteriores na teoria da medição. $\mathrm{O}$ tratamento da linguagem religiosa e ética é uma parte pequena, porém, evidentemente importante, de um projeto desses. O objetivo deste artigo é promover essa parte do projeto. Há indícios, na fase intermediária de Wittgenstein, de uma tentativa de entender a lógica da linguagem religiosa e ética em termos de escalas de caso-limite. Embora Wittgenstein, às vezes, se referisse explicitamente à mensuração, nesses contextos, ele não teve acesso a uma teoria da medição adequadamente desenvolvida e, desse modo, não esteve numa posição que lhe permitisse desenvolver plenamente suas observaçôes. A evolução subsequente da teoria da medição, especificamente no que tange a subgrupos de simetria, é importante para se desenvolver a noção de Wittgenstein de que o ético e o religioso, embora estejam além do domínio do fatual, não ficam fora de todas as formas de lógica ou de medição. Esta obra, portanto, não é uma exegese pura, mas também não é puramente independente da exegese. Ela foi uma tentativa de compreender algumas ideias parcialmente desenvolvidas na obra de Wittgenstein e de compreendê-las melhor, em termos dos desenvolvimentos posteriores na teoria da medição.

BOLENDER, J. The logical form of religious and ethical language. Trans/form/ação, Marília, v. 41, n. 4, p. 155-176, Out./Dez., 2018. 
ABstract: Ludwig Wittgenstein attempted to develop an approach to the philosophy of logic in terms of measurement scales. While he showed great sensitivity to different kinds of scaling, Wittgenstein was not in a good position to bring this project to fruition; measurement theory did not begin to develop significantly until the late 1940s, and only made pertinent advances as late as the 1980s. However, in writings and lectures from the 1930s, Wittgenstein made a number of attempts to understand the logic, or "grammar", of religious and ethical language in relation to measurement. This article is an attempt to develop some of these nascent ideas in intermediate Wittgenstein in terms of later developments in measurement theory. Specifically, it is argued that religious and ethical language are extreme forms of non-empirical and non-factual forms of measurement; they represent the limitcase of measurement.

KeYwords: Wittgenstein. Logical form. Measurement theory. Propositional systems. Measurement scales.

\section{REFERÊNCIAS}

CITRON, G. Religious language as paradigmatic of language in general: Wittgenstein's 1933 Lectures. In: VENTURINHA, N. (Org.). The textual genesis of Wittgenstein's philosophical investigations. Nova York; Londres: Routledge, 2013. p. 19-36.

ELLIS, B. Basic concepts of measurement. Cambridge: Cambridge University Press, 1966.

FISKE, A. P. Structures of social life: The Four Elementary Forms of Human Relations. Nova York: Free Press, 1991.

LUGG, A. Wittgenstein in the mid-1930s: calculi and language-games. In:

VENTURINHA, N. (Org.). The textual genesis of Wittgenstein's philosophical investigations. Nova York; Londres: Routledge, 2013. p. 135-54.

MCGUINNESS, B. (Org.). Ludwig Wittgenstein and the Vienna Circle: conversations recorded by Friedrich Waismann. Tradução de Joachim Schulte e Brian McGuinness. Oxford: Backwell, 1979.

NARENS, L. On the scales of measurement. Journal of Mathematical Psychology, v. 24, n. 3, p. 249-275, 1981.

.; LUCE, R. D. Measurement: the theory of numerical assignment. Psychological Bulletin, v. 99, n. 2, p. 166-180, 1986.

NECHAYEV, S. Catecismo de um revolucionário. 2011. Disponível em: <http://www. teatrodomundo.com.br/o-catecismo-de-um-revolucionario/> . Acesso em: 19 out. 2018.

QUINE, W. V. O. Filosofia da lógica. Tradução de Therezinha Alvim Cannabrava. Rio de Janeiro: Zahar, 1972.

STEVENS, S. S. On the theory of scales of measurement. Science, v. 103, n. 2684, p. 677-680, 1946. 
. Measurement, psychophysics, and utility. In: CHURCHMAND, C. W.;

RATOOSH, R. (Org.). Measurement: definition and theories. Nova York: Wiley, 1959. p. 18-63.

VENTURINHA, N. (Org.). The textual genesis of Wittgenstein's philosophical investigations. Nova York; Londres: Routledge, 2013.

WITTGENSTEIN, L. Some remarks on logical form. Tradução de Eduardo Coutinho Lourenço de Lima. Proceedings of the Aristotelian Society, v. IX, (Supl.), p. 162-171, 1929.. Disponível em: <http://phi.pro.br/trad/wittgenstein.pdfs. Acesso em: 19 out. 2018.

. Tractatus logico-philosophicus. Tradução de José Arthur Giannotti. São Paulo: Editora da Universidade de São Paulo, 1961.

. A lecture on ethics. Tradução de Darlei Dall'Agnol. The Philosophical Review, v. 74, n. 1, p. 3-12, 1965. Disponível em: <https://ateus.net/artigos/filosofia/conferenciasobre-etica/>. Acesso em: 19 out. 2018.

. Lectures and conversations on aesthetics, psychology and religious belief. Organizado por Cyril Barrett. Berkeley; Los Angeles: University of California Press, 1967.

. Philosophische Untersuchungen. Malden, Massachusetts: Blackwell, 2001.

. Gramática filosófica. Tradução para o de inglês de Anthony Kenny. Tradução para

o português de Luís Carlos Borges. Organizado por Rush Rhees. São Paulo: Loyola, 2003.

. Observações filosóficas. Tradução para o inglês de Raymond Hargreaves e Roger White. Tradução para o português de Adail Sobral e Maria Stela Gonçalves. São Paulo: Loyola, 2005.

Recebido: 03/02/2017

Aceito: 23/08/2017 